\title{
From Challenge to Empowerment: Cross-Cultural Experiences and Perceptions of First-Generation Migrant Family Students
}

\author{
Golaleh Makrooni ${ }^{1}$ \\ Tampere University, Finland
}

\begin{abstract}
Although research on migrant students and their education exists, there is a lack of knowledge in Finland about the experiences and perceptions of successful First-Generation Migrant Family Students (FGMFS) in their educational path and transition from school to higher education. Therefore, this study aims to identify the main factors by which these students can successfully shape their educational pathway. Fifteen FGMFS pursuing higher education in Finland were interviewed, and, with the help of Grounded Theory (GT), three main categories - Individualism and Collectivism, Gender Role, and Critical Thinking — were identified as significant in coping with cross-cultural challenges and continuing their study in higher education successfully. The results of this study can help educational institutions create empowering environments to enhance the learning of FGMFS.

Keywords: critical thinking, first-generation migrant family students, gender role, grounded theory, higher education, individualism/collectivism.
\end{abstract}

Education plays a major role in preparing students with a migrant background for the possibility of employability and a better life. Second-generation immigrants are already significantly better educated than their parents (OECD, 2010). However, the educational outcomes of many children in this second-generation population group are not equal to that of the local population. Airas et al.'s (2019) report on Finnish students with immigrant backgrounds confirms this. Thus, strategies must be developed to promote the economic, social, cultural, and political integration of migrants and their children. From the societal point of view, the children and young people of the migrant families must be integrated into the educational system and are also welcomed in educational institutions.

However, few researchers have focused on the skills, challenges, and experiences of First-Generation Migrant Family Students (FGMFS) on their educational path to and within higher education. For example, according to Makrooni (2019), FGMFS agree that they are taught with equality in Finland; however, there is an indication that FGMFS and their teachers perceive equality differently when it comes to understanding the actual ability of these students to continue their studies in high school or vocational school. Nevertheless, little knowledge about these pupils, their capacities, skills, and challenges is available to educators and staff in the Finnish educational system, especially what makes them successful in the cross-cultural context that they experience. In studying students with migrant backgrounds, it is also essential to know and take into account their family and community culture to understand and help these students or FGMFS to develop the social and cross-cultural skills and capacities that can make them successful in their education and also find their position in the host country as welleducated people.

Therefore, this study aims to investigate how FGMFS experience and perceive their educational pathways at school and university in the cross-cultural context in Finland and

\footnotetext{
${ }^{1}$ Correspondent author e-mail: golaleh.makrooni@tuni.fi
} 
discover the interdependent factors that made them successful in their education. In this case, sub-questions were used to investigate how they perceived their cross-cultural experiences on their educational journey, how these perceptions and experiences influenced the development of their success as an FGMFS in higher education, and how their cross-cultural experiences and perceptions on their educational pathway have shaped their new position and their identity. In such, this study provides data to formulate these strategies better and to set objectives for the target group of FGMFS.

\section{First-Generation Students in Higher Education}

Many researchers have studied first-generation college students (FGCS) with and without immigrant backgrounds in the United States, but the results of their studies might be different in Finland. The research on FGCS focuses on different topics, like parents who have had limited access to university education (Choy, 2001; Ishitani, 2003), the grade of ambitions (Abdul Rahim \& Azman, 2010), the lack of self-confidence before arriving at college compared to their peers (Saenz et al., 2007), staying less connected to campus and university life, and actively maintaining family and community roles and responsibilities (Ecklund, 2013). Forrest Cataldi et al. (2018) point out that, in the United States, their graduation rates are lower compared to students from college-educated parents. Furthermore, a larger percentage of firstgeneration university students in the United States come from lower-income households than students of the continuing generation, and they correlate negatively with academic performance and the completion of degrees (Redford \& Hoyer, 2017). Delima (2019) pointed out that better understanding of their lives and their learning experiences is important, and the knowledge that this group of students brings to the classroom needs to be developed and combined with the subjects taught. Castillo-Montoya (2017) found in her study that using previous sociopolitical knowledge of their life experiences can be useful for student learning. Migrant students often have learning difficulties and problems with academic writing, and the challenges for these students in terms of their emotional and social development are characterized by language difficulties and acculturation processes (Ruiz-de-Velasco et al., 2001). However, it is also possible to use the diversity of the campus for successfully developing new teaching strategies (Castillo-Montoya, 2019). Despite these problems, some FGCS with migrant backgrounds are successful. They tend to obtain more university degrees than the locals (Baum \& Flores, 2011), and the enrollment of students from migrant backgrounds brings linguistic, cultural, and ethnic diversity to schools and universities, although these are often ignored or overlooked (Rassool, 1999). Horowitz (2017) mentioned that it is important for the teacher to make this group of students more visible in the classroom and so become their ally in the classroom as a teacher. However, overall, "Most of the literature is focusing on the struggles and the negative outcomes of FGCS, but not many studies have focused on the experiences of the students who have been successful" (Demetriou et al., 2017, p. 35). Further, the results of the Airas et al.'s report (2019) indicate that Finnish students of immigrant and foreign backgrounds have problems attaining, continuing, and finishing higher education, even though they aspire to be successful in higher education.

Indeed, access to higher education is an integral part of improving the lives, opportunities, and possibilities of FGMFS, which will subsequently affect their well-being and improve their social mobility and success in work and life. However, there is a lack of knowledge about how FGMFS experience and perceive their educational journey (school and university), and how they are developing their cross-cultural capacity, and how they find their new position and become successful. Makrooni (2019) found three main categories - family values, institutional values, and friendship-which provided insightful answers of what FGMFS perceived, experienced, and made them successful during their educational journey to higher education in Finland. 
Still, many aspects of FGMFS` life stories are not fully understood, including how they perceive and experience their educational pathway in the cross-cultural context and how these intercultural educational experiences influence their educational success, position, and identity in the context of Finland. Such an understanding will help educational institutions to develop culturally relevant pedagogy for migrant family students to further improve their educational success. These experiences can be used as a basis for promoting the quality of educational institutions; and as a basis for policymakers in creating inclusive environments and policies, from school to higher education, to support FGMFS` learning.

\section{Research Process}

\section{Research Method}

This study uses Grounded Theory (GT) that Glaser and Strauss (1967) developed as a research method. With the help of GT, a theory or construct can be generated (Glaser \& Strauss, 1967). For this purpose, data were systematically collected and analyzed (Strauss \& Corbin, 1994). Existing conceptualizations should not be used in GT. This method allows researchers to find possible data without pre-assumptions. To ensure a high degree of openness, GT was used to discover and describe hidden patterns and constructions of FGMFS ' experiences and perceptions during their successful educational path. In this study, which is part of a doctoral thesis, the emerging theory is limited in the domain of understanding the investigated phenomena in this particular part.

\section{Data Collection}

The registration office, the intranet pages, various faculty members, and the university's Facebook page were used to send an announcement to all students in April 2017. Five students responded; three of them were identified as members of a target group, and most interviewees were identified through a snowball effect. The precisely described announcement created trust in the research and made the aims of the interview clear (Buchanan et al. 1988). Fifteen students (eight female and seven male) were selected because they met the criteria as FGMFS (students in higher education who belong to migrant families and their parents did not have higher education degrees) and were available for the interviews. All participants, except four, came from the second largest university in Finland. Participants'_ages ranged between 25 and 38 years old. Eleven participants were from the Middle East [Iran and Iraq], two from Africa, one from Asia, and one from Russia. There was no presupposition in the selection of participants from a specific group or country, and the majority of Iranians and Iraqis among participants was due to the use of snowball method. Four interviewees had graduated, and the rest were studying various subjects at the master and bachelor levels. One was born in Finland, four arrived between 1 and 5 years old, three between 10 and 13 years old and seven between 16 and 18 years old.

A 90 to 110-minute interview was conducted with each participant from May 2017 to September 2018. For most of the interviews English was used and only three were in their mother tongue. The interviews were recorded using an audio file and then transcribed. According to the grounded theory approach, no attempt was made to verify an existing hypothesis, but rather to follow the principles of grounded theory. An attempt was made to develop a theory based on the data (Rupsiene \& Pranskuniene, 2010). As further data did not lead to any new concepts or dimensions, theoretical saturation was reached after 15 interviews were conducted (Houlton \& Walsh, 2017). 
Data were gathered in an open-ended question format and referred to the experiences and perceptions throughout their educational careers (school and university), always concerning their immigrant background. The questions covered such topics as cross-cultural conflicts and challenges, the influence of school and university on their attitudes, their behavior during their studies, differences they perceived or experienced compared to other Finnish students, their perception of themselves as FGMFS on their educational path, their perception of the way others have positioned them, and strategies in dealing with these two different cultures and values.

The stories of the interviewees were collected and evaluated, and a guideline was developed to get a framework. During this process, further questions emerged related to their lives and the people that have been around them: teachers, friends, relatives, peers, and parents. They were also asked about their emotions, values, challenges, and conflicts caused by the different cultures with which they were faced. This process was done 15 times until no additional relevant data were found, and theoretical saturation was achieved (Aldiabat \& Le Navenec, 2018). The writing of memos was carried out to establish Grounded Theory in the long term and to establish relationships for the next interview. The focus was on the most essential codes that appeared in the previous interviews. Based on the memos, sub-questions were used to investigate how they perceive their cross-cultural experiences about their educational path, how these perceptions and experiences influence their educational pathway development and success as FGMFS in higher education, and how they perceive and experience schools and universities in shaping their new position and developing their identity in an intercultural context.

\section{Data Analysis}

For the data analysis, open, axial, and selective coding was carried out (Strauss \& Corbin, 1994). Through open coding, concepts and key phrases were identified, and data were broken down into conceptual components to help the researcher's reflection on them. The data from each participant was "constantly compared" for similarities. Through coding and constant comparison, ideas are generated, and the conceptual connections between the individual categories are found (Holton \& Walsh, 2017). Selective coding was used to integrate the main categories. This continuous process with the different forms of coding helped to bring the data to a conceptual level and to develop and find the properties of the respective categories and relations among them (Holton \& Walsh, 2017).

Open coding, axial coding, and selective coding were carried out following Strauss and Corbin (1994). The first step of data analysis was to do the open coding; for example, one interviewee pointed out (see A2b, Table 2), "My parents were happy and proud of me, respected me ... but maybe also they got a little bit scared because now I had the power to do something and had more freedom to myself." The open coding was "value of education" and "feeling scared of having power and freedom for children," and the axial code was "changing role and positions through education." These coding steps, rereading the transcriptions, and writing memos were used to find the patterns that were reflected in the data. The final step, selective coding, was applied to integrate the main categories. Glaser and Strauss (1967) pointed out that in a continuously and comparative process of the four steps they developed, the theory will emerge and show saturation. The steps are: "1) comparing incidents applicable to each category, 2) integrating categories and their properties, 3) delimiting the theory, and 4) writing the theory" (p. 105). Realizing a consistent story to understand the cross-cultural context of their educational journey and being successful in the three categories that emerged were related to each other. 


\section{Research Findings}

In selective coding, the main categories are identified by authenticated relationships between the subcategories. In this study, individualism and collectivism (I-C), gender role, and critical thinking were identified as three main categories relating to what FGMFS perceived and experienced in a cross-cultural context from the time that they started their education in Finland until their higher education. These three categories explain not only the cross-cultural challenges they experienced but also their abilities and skills to deal with cultural and social contradictions.

\section{Category One: Individualism and Collectivism}

Being an FGMFS also often means being the first to be confronted with certain specific requirements of the culture in the host country, both in the private sphere and in the school and university environment. There are no concrete instructions from parents for these situations. The FGMFS fall back on what they experience in their own culture to master life. These experiences can be very different, particularly if the cultural gap is significant. The interviewees of this study all came from predominantly collectivist societies (Middle East and Asia). Through the life story of interviewees, the difference between the host culture and the original culture was mentioned repeatedly. Through coding processes, the following key axial codes emerged: individual rights versus group demands, parents' expectation and demands, community expectations and judgments, following one's own cultures and roles, dependent vs. independent, uncertainty in relationships and friendships, and the role of culture in changing attitudes and perceptions.

The interview results show that fulfilling the expectations of parents, relatives, and one's own community in the host society were prioritized. The harmony and relationship with the collective were in the foreground, and even though the mother tongue plays a vital role at home, there were not many conversations between adults and children (quote A2, Table 1).

It is important not to make parents disappointed (quote A5a, Table 1). The demands and expectations of the parents were prioritized so as not to disappoint them; in return, what they want for themselves or what they believe in was put aside (quote A10, Table 1). Parents' expectations that children should help, e.g., with the translator (quote A11, Table 1), were also defined by the parents' demands on the children and the responsibility of children for their parents. In these moments, the individual rights of children who might not be available and attend school were ignored.

The pressure on the students was also evident in other situations, such as friendship, with whom they were going out (quote A9, Table 1), or being friends with the opposite sex (quote A10, Table 1). According to interviewees, for some parents in their communities, friendship was perceived as a threat because these friendships could cause a change in attitudes, leadership, and individual expressions of the lives of their children (quote A13a, Table 1).

Parents' expectations of their children and young adults in terms of marriage, friendship, and the way they lead their own lives were opposite to those of Finnish society, and the parents appear to expect that their children keep up with the dominant traditions and values of their own culture (quote A13b, Table 1). Thus, marriage and having children were expected and that avoiding that was called being selfish (quotes A13c, A14, Table 1).

Interviewees also pointed out that learning about Finnish culture and Finnish attitudes has helped them to organize their daily lives and to set the goal of being different from their prior selves. Success factors were mentioned as the responsibility to change their lives and to build strong relationships with themselves to look towards a better future through hard work; 
they also focused on the organization of their lives rather than victimization and holding on past difficult circumstances (quote A14a, Table 1).

When FGMFS are confronted with the host culture, they carry with them the knowledge and values of their own culture. Because they live in the field of tension between two cultures, their positions, their identities, and understanding of both cultures develop, which also encourages integration and belonging. FGMFS learn to discuss and describe their cross-cultural situation and their origins anew through the many and varied influences of educational institutions. The process of change regarding their cultural identity, and their new role and position in society, has been described here in the context of the experiences of dimension I-C.

\section{Table 1}

Individualism-Collectivism

Interview Quotation

A2 "...We spoke only and watch TV in our language and also with my family, and I did not talk to adults in the discussion at home..."

A5a "...I am really relaxed and do not care about the grades. But I would not want to make my parents disappointed ... because my parents were monitoring my grades..."

A9 "...They [the family] thought if I go outside with my friends [and] I do something wrong. They thought that I cannot have a right of choice..."

A10 "...I know that my family does not like that, for example, if I have a girlfriend, my family did not know about it, because I do not like to make them sad..."

A11 "...I should take care of my family and be with [my mother] as a translator in every meeting for my mom to social, to bank .... I could not enjoy my own age. I was taking care of her things [and have] to feel responsibility more than [they do] ..."

A13a "...My parents encouraged me to have Finnish friends .... Some other parents still do not accept to make Finnish friends because they are afraid that they will change you and make you part of the society when you always have to remember your background and your real culture and what is your real culture...."

A13b “...Finnish society is an individual culture, and we have like a collective culture, so you are expected to be part of the group and part of the little community, and then you are expected to get married and have kids and very traditional staffs .... There are values and traditions we have to keep up with even though you are in Finland ...."

A13c "...If you are doing for yourself, it's like you are selfish because you have a role in the group, and the role is to get married and have kids..."

A14 "...I want to say that if we put ourselves first, it does not mean that you are selfish.... It does not matter if you have this healthy selfishness .... Actually, people just focus too much on others, and what others think about them and why they think like that, so they just think about fulfilling their expectations, and they don't focus on themselves, and that's why our people were miserable.... We have this pain in ourselves."

A14a “...I am one person, but why I am different from tomorrow. I got it from Finnish culture. ... I have very Finnish attitudes on life like Europeans. I try to tell immigrants... to get in school and do this and that. ... [and] don't have a victim mentality.... Instead of blaming them whatever happened, you take the responsibility of changing and building a good relationship with self as the longest relationship is a relationship with ourselves...." 


\section{Category Two: Gender Role}

The results of the interviews indicated that gender role and gender inequity was one of the selective categories. Through the open coding and, subsequently, the axial coding, the following key axial codes emerged: Gender and following traditional roles, gender inequity, changing patterns of life and thinking, gender and independence, higher education and changing role.

This traditional understanding of roles for young girls or women was evident in many different situations. Women and girls need to be protected and cannot be far or abroad when they are studying (quote A14d, Table 2); they have to be at home at a certain time, they can only go to a party or event up to a certain time. Going out with friends is limited, and freedom is applied differently (quotes A5c, A9, Table 2), but being home early hinders social life in the host society with different cultural expectations (quote A5c, Table 2). The families reinforce the traditional roles for women. That includes marriage, childcare, and household affairs (quotes A2a, A13b, Table 2). There is a very traditional understanding of the role of men. Men have to protect women and have a specific role (quotes A5a, A14a, Table 2). For the interviewees, independence caused conflicts and dissatisfaction amongst their families. Female interviewees have experienced tangible differences in treatment, expectations, and roles between home and society. This often leads to inner-family conflicts (quotes A2c, A5b, A13b, A14d, Table 2) that vary depending on the cultural and individual background, openness, or personal convictions of the parents. Although interviews demonstrated the value of education and encouragement to study from parents, some parents seem to fear that their daughters will have access to higher education because of the resulting increased independence and freedom for their daughters (quote A2b, Table 2).

Additionally, males are confronted with these traditional attitudes. On the one hand, the parents were proud that their sons were studying, but had difficulties with them leaving the family (as this was not so common in their own culture), as well as having friends of the opposite sex (quote A10, Table 1). Moreover, due to different cultural norms, men are not accustomed to talking about education at home or showing their feelings and emotions; this somehow creates distance between the parents and their sons (quote A1, Table 2). In the interviews, it was also pointed out that sons had difficulties at school and with learning the Finnish language, or often dropped out (quote A13a, Table 2).

However, the FGMFS not only break the traditional educational paths, but they also change and overcome traditional beliefs. They want to progress and do not want to experience similar roles as their mothers or other uneducated relatives (quotes A3a, A3b, Table 2). The female students at school experience gender equality. Teachers with intercultural awareness and encouragement played a significant role in this process (quote A14b, Table 2). In such an environment, female FGMFS want to study, be successful, and gain the same position and opportunities as men (quotes A3b, A13c, A14c, Table 2). Therefore, they must work hard to be successful, and they see education as a tool to gain power in life and to change educational and role patterns. For female FGMFS, the examination of their own roles that they experienced in contrast between family and society has an essential function in their identity development. Overall, despite facing cultural challenges and barriers, the chances of first-generation female students in Finland are considered good for improving gender equality and gender roles.

Table 2

Gender Role

\begin{tabular}{ll}
\hline Interview & \multicolumn{1}{c}{ Quotation } \\
\hline A1 & "...My parents did not talk about my education, because I did not want to talk about \\
& my problems .... My mom talked with my sister more than me...."
\end{tabular}


A2a “...At weddings ..., I just look at girls at my age, they have children, ... do not work in any place ... do not have even high school diploma... and [that] makes me sad...."

A2b “...My parents ... [are] happy and proud of me and respect me .... [It] is hard in Finland to get into a university. Also, they got a little bit scared because now I have the power to do something and had more freedom to myself..."

A2c "...I want to move alone and get my own apartment... but my parents told me if you want to move it is ok, but it is not normal in our culture to live alone .... They resisted for a while, but then they accepted it...."

A3a "...I did not like to be like my mom illiterate or like my other relatives that are not well educated ... just stayed at home, girls also ... are not so highly educated.... I wanted to progress and study...."

A3b "...I wanted to show that as a woman I can also be successful .... Women can improve and progress and have higher education and work and be independent...."

A5a "...My parents were afraid.... Girls in our culture and family have to be supposed and to be protected.... A Finnish lady helped me to move and live on my own....".

A5b "...Gradually, after fighting in half a year, I got to move on my own when I started my university...."

A5c “...My parents wanted me home before $10 \mathrm{pm} .$. actually no social life with your friends ... When your friends say, ... let's go to drink... go to the student party ... I cannot .... My mom ... was waiting for me, so socially, it was so hard. At home, we had another cultural expectation...."

A9 “...Freedom in my family [is viewed] as something else. ... If I go out with my friends, I do something wrong. ... I cannot have a right to choose .... They should decide...."

A13a "...My brother had problems with school, so I was the good one who wanted to study. ... My parents were proud of me and lectured my brother. He did not like to go to school, did not study, ... no secondary degree. He now works at the restaurant...."

A13b “...Women in [our] own society are not equal to men, so I did a lot of work to gain that.... I am very ambitious, ... want to study, ... be successful have my degree, ... be equal to a man because you are equal to a man and through your education. My family and my own community have been taught and strongly believe that the women are not equal .... It becomes a conflict if you say that it is not true...."

A13c "...Our society treats boys and girls in different ways; they give boys more freedom. In a masculine society, you need to prove yourself [as a woman] somehow, and you need to work extra hard to earn to be equal...."

A14a "...I saw the treatment of how in I had an equal raise up in Finland and living with Finns. However, when I grew up, I was faced with comments like I am a flower or you know a girl that should be protected ... from my family, so I knew culture is a power...."

A14b “...In secondary school ... an amazing and smart teacher ... cared about the immigrant's children and mostly about the girls, ... and told me that girls like you with an education do not need anyone .... You have the power when you have an education, and that stuck in my mind ...."

A14c "...People told me ... going to high school that is so hard .... You are not going to make it. I have good grades... and I am going to try. ... My friends are going there.... People told me you cannot do it ... because you are a girl, ... that gave me more power to show them or show myself...."

A14d “...I won in one competition .... My family said congratulations, but you don't go anywhere without us. My older brother told me you are not going because you are a girl, and I am a boy. That was a breaking point. So, I decided to leave home..." 


\section{Category Three: Critical Thinking}

Critical thinking (CT) was identified in this study as another important dimension. However, few researchers have focused on FGMFS or FGCS and critical thinking. Cognitive skills like comparing were used for their work and academic performance, as well as how hard one studied and worked and how many hours one had to invest to keep up with one's Finnish schoolmates. The comparison also leads to a high degree of self-regulation (quotes A4, A6, Table 3). How parents communicate at home and with their friends is very different from what FGMFS have learned from their education at school and university, and these differences are compared, explained, and analyzed.

Interviewees noted that the argumentation patterns and opinions would not contain different points of view at home, in contrast to the university environment (quote A2, Table 3). For some, discussion of cultural issues with their families was not a significant concern, and they felt that the presence of two cultures was a benefit that enabled them to see from different angles and think differently (quotes A12, A14, A13d, Table 3). Asking questions (included asking oneself) was also frequently mentioned, referring to their grades and studying (quote A4, Table 3), as well as asking questions and evaluating oneself for personal growth (quote A8, Table 3). It was also pointed out that in Finnish education, asking questions from kindergarten onwards helps to stimulate curiosity and in-depth thinking (quote A13a, Table3). Moreover, the critical role of higher education in questioning and openness in the discussion was pointed out and highlighted (quotes A13b, A2 Table 3). Furthermore, education and study have increased their self-confidence and self-efficacy (quotes A11, A13d, Table 3).

The use of cognitive skills for interviewees shows incredible development. Facione (2013) assumes that critical thinking is more than a list of cognitive abilities. Critical thinking is also referred to as a "disposition," which leads to the reverse conclusion that critical thinking is a ubiquitous and purposeful human phenomenon. Basically, the interviews were full of references to these cognitive skills and how valuable they were considered for one's life.

Critical thinking can be seen as an essential category in the development of one's own cross-cultural identity and finding one's position in society and their culture. The skills in argumentation and discussion helped FGMFS to indicate their own new position in the field of tension between one's own origins and the new culture, and in questioning and searching for logical reasons instead of accepting their position based solely on cultural norms (quote A13c, Table 3). They analyzed and explained their understanding of culture as sand in water, which can be shaped and not fixed forever like carved on the rock (quote A14, Table 3). This way of thinking and analyzing shows the ability to question critical aspects of the existing culture and the position that may be forced upon it.

\section{Table 3}

\section{Critical Thinking}

\begin{tabular}{ll}
\hline Interview & \multicolumn{1}{c}{ Quotation } \\
\hline A2 & "...Here at university, you have to think ...from different sides about the \\
& subject.... My family talked at home and with their friends with big and strong \\
& opinions without considering different views...." \\
"... I have problems with [learning] stuff .... I did not get a good score ... and \\
asking myself, is it because of the language? .... I came to the solution just by \\
myself that to do something better ... get a good score and continuing schooling, \\
encourage myself, ... worked harder, and I do not give up myself...." \\
"...I had some challenges during my education. ... I always knew that anything \\
like that, the only solution is myself and my behaviors, the solution is myself \\
and my efforts...."
\end{tabular}


A8 “...I like to analyze many things, specifically analyzing myself. Most of the time, I like to think about my actions, why I do, and how I react to something."

A11 "...Here education made me think you know thinking about information that I got, but in my home country, we just repeat the materials without understanding... I learned to like being independent, being strong, and trusting myself more."

A12 “... Discussion about cultural differences at home with family ..., parents ... you should do this, do not reject this... To be honest, we do not see it as a problem of being in between two cultures. On the contrary, it has an advantage. We can see things in different ways, can always compare things... can choose ... compare to people who have only like one culture...."

A13a "...Here they are teaching you from kindergarten to question everything, do not take anything like given to you. I argument much better than they [parents] do ... because I have the tools to have argumentation...."

A13b “... University in Finland tries to concentrate on questioning everything, ... I question everything at the beginning .... I look at things from many different perspectives and not having the absolute answer. ... When I got to the university, I think I learned to discuss... accept the fact that something disagrees with me ... accept the fact that we think differently ...."

A13c " "...There are some structural atmospheres in the culture where have been created throughout the years .... they do not have any explanation for [many things]. ... they [community] are not willing to change their opinion, ... I want to prove my position just because they say that, ... but I am learning my position as an equal human being...."

A13d "...When I went to high school, I realized that being different is my superpower...."

A14 “...When I was young, I do not like my own culture and willing to be Finnish, but now...I see that there are both sides and I can mix the good sides. I realize that culture is changing all the time, and we determine the culture.... I realize that culture has not been carved in a rock, and you can break. It is like sand in water, and you can change it...."

\section{Discussion}

Makrooni (2019) described three important categories - institutional values, family values, and friendship - that help FGMFS to benefit from their educational journey to continue and complete their education. The important emerging conceptual element that links these categories is openness. Besides these categories, this study identifies three other vital categories that contribute to the academic success of FGMFS and help them to change and successfully develop preconceived patterns of their culture, roles, and thinking in the cross-cultural context. These include the culture-specific categories of individualism and collectivism, gender roles, and critical thinking.

The results for the first category tend to be similar to one main finding of Hofstede (2011), which is individualism versus collectivism. Individualism refers to personal goals and rights, while collectivism is more focused on group goals and demands, as well as how personal relationships are organized within the group. In their study, Schwartz et al. (2013) found that individualistic values are positively related to psychological and eudaimonic well-being. Yaman et al. (2010) and pointed out that Dutch mothers, in comparison to Turkish immigrant mothers, who belong to collectivist-oriented families exercise more authoritative control and do not show high respect for the autonomy of the children. These results were in line with the 
findings of this study when the expectations of the family and one's community in the host country were mentioned in the interviews as expectations to be fulfilled with priority.

In collectivist cultures, groups and families are usually very large, and group ties are correspondingly strong. In individualistic cultures, on the other hand, individual self-realization and the nuclear family are prioritized; children learn to think in the I-form versus the We-form (Hofstede, 1983). Individual identity must be considered in close connection with a collective identity. Most researchers agree that Finland is an individualistic culture with strong institutional collectivism (Hofstede, 2011).

According to Gudykunst and Nishida (1999), the interaction of an individual's strength of cultural identity with cultural background influences his/her individualistic and collectivistic values. Gonzales et al. (2014) pointed out that identity is constructed because of the dual influences of home and host culture. At the same time, however, by perceiving and questioning the values of one's own family and culture due to the cultural dimension I-S, other values, norms, and social roles are newly learned and adopted. This, in turn, has an impact on the shaping of social relationships, on one's own behavior, on the way one communicates, and what one expects from one's family. Additionally, the family also influences them. When two different cultures form you, you should be empowered to make independent decisions and follow the path you believe in that is right. Berry et al. (2006) defined this process of cultural and psychological change, which arises from intercultural contacts, as acculturation.

The second category, gender roles, has the strongest and most lasting significance for the female respondents in this study and leads to significant changes in their lives, their selfidentity, their role, and their position. They perceive different treatment and expectations only because of gender. They experience differences in social life and their roles in comparison with what they learned and experienced with their Finnish classmates and friends. Freedom has a different meaning in their own culture than in Finnish culture, because freedom in the Finnish context is positively loaded; in their own culture, the role and rights of women are usually negatively loaded. The results of the interviews show that they recognize the positive meaning of freedom and equality and want to live and be treated as such.

However, they want these changes not only for themselves but also for the whole community and society in which they live. To do this, they must be empowered to have the necessary skills, be independent, and have control over their own lives. They want to achieve these skills and new positions through higher education. Meanwhile, they appreciate their own culture and norms and see advantages of their own culture, but they are willing to change the factors that are contrary to what they have achieved in their educational journey in the host society. Very important and very effective, of course, is for women to achieve equality, independence, and freedom.

The male interviewees also want a different position and a different role. While they may be forced into specific roles, they are often not confronted with gender inequity. This confrontation was not particularly highlighted in the interviews by the men as opposed to the women, even though they still involve collectivistic cultures and norms, for example, in case of their relationship with the opposite sex and fulfilling their parents' expectations. However, also, they want to change their position from a migrant or refugee to a functioning and active citizen. They want to change their economic situation, as well as the social and cultural structures of the community from which they come. Two of the male interviewees studied at both high school and vocational schools at the same time to ensure their professional and academic success. Their hard work indicates their diligence to achieve a better situation in their lives. For both female and male interviewees, it is a desire to be active citizens in the host society, but also a desire to change the tradition of their own community where it makes sense; for example, in the case of a good role model or their future profession, helping other immigrant family students and even development cooperation with their own country of origin. 
The findings are in line with other researchers. Ravecca (2010) pointed out that school experiences of immigrant boys and girls or those with a migrant background generally reflect the models of gender differentiation of precisely the country of arrival. The greater control that families have over daughters can be traced back to traditional gender roles. However, young migrant women often manage to compensate in just one generation for the stressful pattern of educational and professional integration that has shaped their parents' lives in their country of origin (Feliciano \& Rumbaut, 2005; Zhou \& Bankston, 2001). What we also find is what Cervantes (2010) describes as machismo for boys, which is characterized by superiority and the roles of being a provider and protector.

According to previous studies, daughters of immigrant parents tend to achieve better school results than boys (Dale et al., 2002). Girls also have lower drop-out rates (Brinbaum \& Cebolla-Boado, 2007) and higher educational aspirations, with a broader gap between girls and boys than what is seen in the indigenous population (Barajas \& Pierce, 2001; Fuligni \&Witkow, 2004). Even though educational expectations are important predictors of success, the determinants of outcomes are significantly gendered based, showing that educational pathways are not segmented just by ethnicity and class (Feliciano \& Rumbaut, 2005). This can be seen in the interviews as well. The brothers of the female interviewees (while they talked about their siblings` education) had difficulties at school and with learning the Finnish language or dropped out. The girls wanted to learn, wanted to change, and wanted to take part in society and live as they experienced it at school and in Finland.

For the third category, critical thinking, a few studies in the context of FGMFS; e.g., Terenzini et al. (1996) demonstrate that FGCS choose less demanding courses in secondary education and, therefore, they suspected that this could be an explanation for the weaker cognitive abilities of students in reading comprehension, mathematics, and critical thinking. Critical thinking was evident in the interviewees of this study at the level of axial coding in both cognitive abilities such as questioning, explaining, arguing, analyzing, comparing, selfevaluation and adapting, solving problems, searching for a solution, self-regulation, selfcorrection, and abilities like open-mindedness and judgment. These skills are in line with the important critical thinking skills posited by Facione (1990) and Facione et al. (2000). This is also in line with Demetriou et al. (2017, p. 32) argument that successful FGCS have developed the dispositions of "(a) being flexible and willing to change, (b) feeling independent, (c) perceiving challenges as opportunities for growth, and (d) risk-taking," possibly during their studies.

Critical thinking is thinking that focuses on deciding what to believe and to do, which is also a "practical activity" (Ennis, 1985). In general, critical thinking means being fair and open when considering different views, trying to understand issues deeply, being curious, questioning assumptions, considering evidence and limitations, being persistent on seeking logic, being cautious, being humble, recognizing one's own limitations, and admitting when one is wrong or not knowing. Critical thinking plays an essential and unique role in the development of thinking and identity for FGMFS, which became very clear in the interviews. In the interviews, almost all skills that Facione (1990) mentioned in the cognitive, dispositional, and academic areas were described for different experiences in the family. The questioning of one's own culture becomes particularly apparent with the female interviewees when they are confronted with differences in values and roles. They begin to think, question, analyze, and synthesize, and then reflect. They then make decisions based on their experiences at school and university. Therefore, the critical thinking skills that they have learned and practiced in the institutions, gave them this ability, along with the confidence to go through this process of contradiction and cross-cultural challenges successfully. Critical thinking for both men and women also arose from self-assessment and self-correction in coping with academic challenges, such as getting enough ECTS points and good scores during their study in Finnish. Overall, CT empowers the FGMFS to use their educational pathways successfully. 
These three categories-I-C, gender role, and critical thinking - emerged in this study, influencing the educational pathway of FGMFS successfully toward higher education and empowering them. All these cross-cultural experiences on their educational pathway in learning institutions were always confronted with an additional and different cultural context that what they experience at home with their families and communities. For these students, living in the cross-cultural context means looking at many situations from a different, broader perspective, and simultaneously living in two learning environments. The results of this study show how FGMFS' cross-cultural experiences and perceptions develop their cross-cultural identity and help them to shape their new position in the host society; broaden their viewpoint and horizon of thinking; and see, analyze, and discuss values, rules, and norms from two perspectives.

All this leads to what we could call an "innovative adaptive strategy"-not just to cope with different barriers, but also to be able to use one's strengths to overcome obstacles and to break the cultural and social pattern, thus paving the way for other migrant family students. Using the adaptive strategy is explaining a movement from being weak to successful; from being different and feeling weakness to being a person with a superpower with an active role in society; and being proud to be the first one in the family at university, and thus, a good role model. The instrument to realize these positive changes is education.

As a result, the cross-cultural experiences and perceptions of the FGMFS on their educational journey have a role in the empowerment process, which shapes their cross-cultural identity and makes them able to gain new positions by acquiring the ability to internalize two cultures through continuing their education. The forms of expression the participants used are quite different, show an interesting range, and are described in an expressive language. For example, they discuss seeing themselves as "belonging to a third culture," "being different is my superpower," or "I do not believe in nationality and what matters is humanity." Overall, all of the interviewees see education in the cross-cultural context as an instrument to gain power, to change their destiny, to find a better position to be able to be influential in overcoming the cultural and social obstacles and in fighting for justice by working and studying hard.

\section{Conclusion}

In this study, three main categories emerged, among which are collectivism and individualism, gender role, and critical thinking. The linkage among these three main categories is best explained by empowerment in the context of their cross-cultural experiences. Empowerment emerged as the conceptual element linking these categories, showing how the development of one's own cultural identity has been influenced and shaped by the recognition of differences and the use of skills taught by educational institutions and supported by higher education. This plays an important role in understanding how social and cultural patterns can be changed, how cross-cultural identity is developed, and what leads to success in attending higher education and finding one's own way into Finnish society.

All the categories that emerged provide insightful answers to the research question of what an FGMFS perceives and experiences on their educational pathway from school to higher education in the cross-cultural context in Finland. Through their experiences and perceptions of life in a cross-cultural environment, they developed innovative adaptation strategies to be successful through a new position in this development process. The participants also realized that they could not change social and cultural thought patterns without hard work and further education, which is why they use their higher education as a tool for self-empowerment. Through the empowerment of students and openness, institutional education can help this target group to complete their educational journey successfully. All three categories are components that certainly contribute to the development and shaping of cross-cultural identity; however, to 
what extent, this study cannot achieve and precisely determine, and more research should be conducted.

\section{Funding Details}

The author received no financial support for the research, authorship, and/or publication of this article

\section{Disclosure Statement}

The author reported no potential conflict of interest.

\section{References}

Abdul Rahim, A. H., \& Azman, N. (2010). Educational aspirations among first-generation students and their parental influence towards pursuing tertiary education. ProcediaSocial and Behavioral Sciences, 7(c), 414-418. https://doi.org/10.1016/j.sbspro.2010.10.056

Airas, M., Delahunty, D., Laitinen, M. Shemsedini, G., Stenberg, H., Saarilammi, M., Sarparanta, T., Vuori, H., \& Väätäinen, H. (2019). Background matters. Students with an immigrant background in higher education. National Center for Educational Assessment. https://karvi.fi/app/uploads/2019/11/KARVI_2219.pdf

Aldiabat, K. M., \& Le Navenec, C. (2018). Data saturation: The mysterious step in grounded theory method. The Qualitative Report, 23(1), 245-261. https://nsuworks.nova.edu/tqr/vol23 /iss 1/18

Barajas, H. L., \& Pierce, J. L. (2001). The significance of race and gender in school success among Latinas and Latinos in college. Gender and Society, 15(6), 859-878. https://doi.org/ 10.1177/089124301015006005

Baum, S., \& Flores, S. M. (2011). Higher education and children in immigrant families. The Future of Children. 21(1), 193-171. https://doi.org/10.1353/foc.2011.0000

Berry, J. W., Phinney, J. S., Sam, D. L., \& Vedder, P. (2006). Immigrant youth: Acculturation, identity, and adaptation. International Association for Applied Psychology, 55(3), 303332. https://doi.org/10.1111/j.1464-0597.2006.00256.x

Brinbaum, Y., \& Cebolla-Boado, H. (2007). The school careers of ethnic minority youth in France. Success or disillusion? SAGE Publications, 7(3), 445-474. https://doi.org/10.1177/ 146879680708023

Buchanan, D., Boddy, D., \& McCalman, J. (1988). Getting in, getting on, getting out and getting back. In A. Bryman, A. (Ed.), Doing research in organizations (pp. 53-67). Routledge.

Castillo-Montoya, M. (2017). Deepening understanding of prior knowledge: What diverse firstgeneration college students in the U.S. can teach us. Teaching in Higher Education, 22(5), 587-603. https://doi.org/10.1080/13562517.2016.1273208

Castillo-Montoya, M. (2019). Professors' pedagogical strategies for teaching through diversity. The review of higher education, 42(5), 199-226. https://doi.org/10.1353/rhe.2019.0050

Cervantes, A. G. (2010). Breaking stereotypes by obtaining a higher education: Latinas' family values and tradition on the school institution. McNair Scholars Journal, 14(1), 23-54. http://scholarworks.gvsu.edu/mcnair/vol14/iss1/4.

Choy, S. P. (2001). Students whose parents did not go to college: Postsecondary access, persistence, and attainment. Findings from the condition of education. National Center for Education Statistics. https://nces.ed.gov/pubs2001/2001072_Essay.pdf 
Dale, A., Shaheen. N., Kalra, V., \& Fieldhous, S. E. (2002). Routes into education and employment for young Pakistani and Bangladeshi women in the UK. Ethnic and Racial Studies, 25(6), 942-968. https://doi.org/10.1080/0141987022000009386

Delima, D. G. (2019). Making a case for a funds of knowledge approach to teaching and learning for first-generation college students. College Teaching, 67(4), 205-209. https://doi.org/10.1080/87567555.2019.1630355

Demetriou, C., Meece, J., Eaker-Rich, D., \& Powell, C. (2017). The activities, roles, and relationships of successful first-generation college students. Journal of College Student Development, 58(1), 19-36. https://doi.org/10.1353/csd.2017.0001

Ecklund, K. (2013). First-generation social and ethnic minority students in Christian universities: Student recommendations for successful support of diverse students. Christian Higher Education Journal, 12(3), 159-180. https://doi.org/10.1080/15363759.2011.598377

Ennis, R. H. (1985). The logical basis for measuring CT skills (EJ327936). Educational Leadership, 43(2), 44-48. ERIC.

Facione, P. A. (1990). Critical thinking: A statement of expert consensus for purposes of educational assessment and instruction (The Delphi Report) (ED315423). The California Academic Press. ERIC. https://files.eric.ed.gov/fulltext/ED315423.pdf

Facione, P. A. (2013). Critical thinking: What it is and why it counts. The California Academic Press. https://www.nyack.edu/files/CT_What_Why_2013.pdf

Facione, P. A., Facione. N. C., \& Giancarlo, C. A. (2000). The disposition toward critical thinking: Its character, measurement, and relationship to critical thinking skill. Informal Logic, 20(1), 61-84. https://doi.org/10.22329/il.v20i1.2254

Feliciano, C., \& Rumbaut, R. G. (2005). Gendered paths: Educational and occupational expectations and outcomes among adult children of immigrants. Ethnic and Racial Studies, 28(6), 1087-1118. https://doi.org/10.1080/01419870500224406

Forrest Cataldi, F., Bennett, C. T., \& Chen, X. (2018). First-generation students college access, persistence, and postbachelor's outcomes (NCES 2018-421). U.S. Department of Education. National Center for Education Statistics. https://nces.ed.gov/pubs2018/2018421.pdf

Fuligni, A. J., \& Witkow, M. (2004). The postsecondary educational progress of youth from immigrant families. Journal of Research on Adolescence, 14(2), 159-183. https://doi.org/ 10.1111/j.1532-7795.2004.01402002.x

Glaser, B. G., \& Strauss, A. L. (1967). The discovery of grounded theory: Strategies for qualitative research. Aldine Transition. http://www.sxf.uevora.pt/wpcontent/uploads/2013/03/ Glaser_1967.pdf

Gonzales, L. M., \& Eades, M. P., \& Supple. A. J. (2014). School community engaging with immigrant youth: Incorporating personal/social development and ethnic identity development. School Community Journal, 24(1), 99-117.

Gudykunst, W. B., \& Nishida, T. (1999). The influence of culture and strength of cultural identity on individual values in Japan and the United States. Intercultural Communication Studies, 9(1), 1-18.

Hofstede, G. (1983). National cultures in four dimensions: A research-based theory of cultural differences among nations. International Studies of Management \& Organization, 13(1/2), 46-74. https://doi.org/10.1080/00208825.1983.11656358

Hofstede, G. (2011). Dimensionalizing cultures: The Hofstede model in context. Online Readings in Psychology and Culture, Unit 2, Article 8. https://doi.org/10.9707/23070919.1014

Holton, J. A., \& Walsh, I. (2017). Classic grounded theory. SAGE Publications. 
Horowitz, G. (2017). First-generation college students: How to recognize them and be their ally and advocate. Journal of College Science Teaching, 46(6), 8-9. https://doi.org/10.2505/4/jcst17_046_06_8

Ishitani, T. T. (2003). A longitudinal approach to assessing attrition behavior among firstgeneration students: Time-varying effects of pre-college characteristics. Research in Higher Education, 4(4), 433- 449. https://doi.org/10.1023/A:1024284932709

Makrooni, G. (2019). Being a First-Generation Migrant Family Student in Finland: Perceptions and experiences of the Educational Journey to Higher Education. Journal of Ethnic and Cultural Studies,6(3),157-170. http://dx.doi.org/10.29333/ejecs/293

OECD. (2010). PISA 2009 results: Executive summary. https://www.oecd.org/pisa/pisaproducts/ 46619703.pdf

Rassool, N. (1999). Flexible identities: Exploring race and gender issues among a group of immigrant pupils in an inner-city comprehensive school. British Journal of Sociology of Education, 20(1), 23-36. https://doi.org/10.1080/01425699995470

Ravecca, A. (2010). Immigrant children school experience: How gender influences social capital formation and fruition? Italian Journal of Sociology of Education, 2(1), 49-73. https://doi.org/10.14658/pupj-ijse-2010-1-3

Redford, J., \& Hoyer. K. M. (2017). First-generation and continuing-generation college students: A comparison of high school and postsecondary experiences. U.S. Department of Education. National Center for Education Statistics. https://nces.ed.gov/pubsearch/pubsinfo.asp?pubid=2018009

Ruiz-de-Velasco, J., Fix, M., \& Chu Clewell, B. (2001). Overlooked and underserved: Immigrant students in U.S. secondary schools (ED449275). ERIC. The Urban Institute.

Rupsiene, L., \& Pranskuniene, R. (2010). The variety of grounded theory: Different versions of the same method or different methods? Social Sciences 4(70), 7-20.

Saenz, V. B., Hurtado, S., Barrera, D., Wolf, D., \& Yeung, F. (2007). First in my family: A profile of first-generation college students at four-year institutions since 1971. Cooperative Institutional Research Program, Higher Education Research Institute, University of California. https://www.heri.ucla.edu/PDFs/pubs/TFS/Special/Monographs/FirstInMyFamily.pdf

Schwartz, S. J., Kim, S. Y., Whitbourne, S. K., Zamboanga, B. L., Weisskirch, R. S., Forthun, L. F., Vazsonyi, A. T., Beyers, W., \& Luyckx, K. (2013). Converging identities: Dimensions of acculturation and personal identity status among immigrant college students. Cultural Diversity and Ethnic Minority Psychology, 19(2), 155-165. https://doi.org/10.1037/ a0030753

Strauss, A., \& Corbin, J. (1994). Grounded theory methodology-An overview. In K. D. Norman \& S. L. Y. Vannaeds (Eds.), Handbook of qualitative research (pp. 22-23). SAGE Publications.

Terenzini, P. T, Springer, L., Yaeger, P. M., Pascarella, E. T., \& Nora, A. (1996). Firstgeneration college students: Characteristics, experiences, and cognitive development. Research in Higher Education, 37(1), 1-22. https://doi.org/10.1007/BF01680039

Yaman, A., Mesman, J., van Ijzendoorn, M. H., Bakermans-Kranenburg, M. J., \& Linting, M. (2010). Parenting in an individualistic culture with a collectivistic cultural background: The case of Turkish immigrant families with toddlers in the Netherlands. Journal of Child and Family Studies, 19, 617-628. https://doi.org/10.1007/s 10826-009-9346-y

Zhou, M., \& Bankston, C. L. (2001). Family pressure and the educational experience of the daughters of Vietnamese refugees. Journal of International Migration, 39(4),133-151. https://doi.org/10.1111/1468-2435.00165 


\section{Notes on Contributors}

Golaleh Makrooni is a $\mathrm{PhD}$ researcher at the Faculty of Education and Culture at Tampere University, Finland and currently lecturer and coordinator for an online course at the Finnish University Partnership for International Development (UniPID, Finland). She holds a MA in History and Philosophy of Education and a BS in Civil Engineering in Iran. Her main research interests are in higher education, adult and vocational education, cross-cultural studies and migration. 